egneuro, 01(02):36-38, 2019

\title{
Safety Measures In Neuro-Surgical Theatre: An Institutional
}

\section{Protocal.}

\author{
Kaushila Dhimal, ${ }^{1}$ Punam Limbu, ${ }^{1}$ Pushpa Biswakarma ${ }^{1}$ \\ ${ }^{1}$ Neurosurgery Operation Theatre, B \& C Medical College and Teaching Hospital \& \\ Research Center,Birtamode,Jhapa,Nepal
}

\section{Correspondence:}

RN Kaushila Dhimal

Neurosurgery Operation Theatre, B \& C Medical College and Teaching Hospital \& Research Center,Birtamode,Jhapa,Nepal.

Email: kausiladhimal5@gmail.com

\begin{abstract}
Effective teamwork in the operating theatre is of vital importance for same and smooth surgery.The main goal of safety measures is to reduce mortality, morbidity, improves communication and team work ,reduce operation time, ensuring the patient is secure in operation table, and also to ensure the operating staff and surgeons from advertent injuries.
\end{abstract}

Key Words: theatre safety, neurosurgical theatre, sharp instruments, drill safety

$\mathrm{I}$

$\mathrm{n}$ this article, we are discussing some very important methods of safety measures in neurosurgical theatre.

\section{Pre-operative safety measures:}

All the instruments should be checked for its malfunction eg;drills used for caraniotomies or spinal surgeries, cautry machine, OT focus light.

Logical sequence of case posting should be followed: ${ }^{1,2}$

(a) Clean case to contaminated case: clean case especially the elective cases where implants are used for eg;cranioplasty, vp-shunt, ACDF etc. should be listed first.
Contaminated cases especially those which are infected or abscesses, are preferred to get listed last; if not, theatre which are dedicated to perform the infected theatre should be used.

(b)Extreme of ages to adult: priority should be given to small and old age group of patient rather then adult because of their rapidly changing metabolism .

(2)Correct patient, correct side and correct side: ${ }^{3}$

This is of utmost important especially when the site and side is not obvious once the patient is anaesthetized. Like the cases of trigeminal neuralgia, brain tumor, lumbar discs, and so on. 
In our theatre, before posting any elective case priorly thorough cleaning of the theatre is done, followed by fumigation of OT using $200 \mathrm{ml}$ of silvicide with $800 \mathrm{ml}$ of distil water making it $1000 \mathrm{ml}$ and intraoperatively traffic controlit means minimizing the health care team inside the theatre to prevent the risk of infection.

Another useful tool to promote patient safety in the surgical setting is the surgical safety checklist published by the World Health Organization.the checklist is based on the successful international program "safe surgery saves lives" which incorporates validated checklist to be reviewed by the surgical team before induction of anesthesia,before skin incision and before patient leaves the operating room. ${ }^{4}$

Intra -operative safety measures:

It is during the cases, there should be proper co-ordination between the nurses and the surgeon.Here, we mainly discuss on Instruments safety and its handling

(1) Safety measures during handling Sharp instruments eg; shown in figure- $1,2,3$

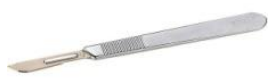

Figure 1: $\quad$ Scalpel source:https://www.westlab.com.au/labware/labwar e-a-m/blades/663-260-disposable-scalpel22-pack-10

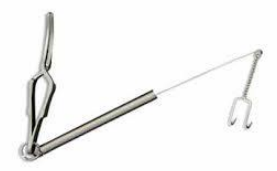

Fig:-2 Fish hook source:https://dtrmedical.com/products/yasargilretractor/

egneuro, Volume 01, Issue 02, 2019
(2) Vicious instrument :- eg; shown in figure- 2

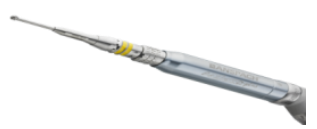

Fig:-3 High Speed Drill source:https://www.depuysynthes.com/hcp/powertools/products/qs/Anspach-EMax-2-Plus-US

- Whenever we pass the sharp instruments should be done in safe way, better to prefer in kidney tray.

- Never pass the instruments over the surgical field.

- Stay away from retractors blades,

- Whenever we pass or store the drill we have to make sure it is not rotating and avoid gauze around it.

- Never touch the instruments when the surgeon is handling it.

- All the instruments should be kept properly and we should also avoid keeping them over patient to prevent falling.

\section{Safety Measures During Sero- Positive Case $^{5}$}

If case should be done for sero- positive patient extra precaution should be taken by all the health care team.

Some of safety measures during positive case are discuss below:-

Pre-operative Preparation:

keep only necessary things inside theatre.

Use of disopasable drapes i.e glass,boots,masks, disposable scrubs gown etc are encouraged, to prevent spread of infection to other patients. 
Intra-operative: try to use only limited instruments.

- Strict handling of sharp instruments.

- Traffic control inside theatre

- Adequate hemostasis in each steps.

- Avoid unnecessary irrigation and proper disposal of the irrigated fluid in a bucket is preferred.

\section{Waste Disposal:}

All disposable item should be kept in separate bucket and disposed in appropriate place taking safety measures. for eg; linen,cautry should be discarded properly.

Post-disposal theatre cleaning in our center, we clean theatre and fumigate immediately

\section{References:}

1. Dexter F, Macario A, Traub RD. Optimal sequencing of urgent surgical cases. J Clin Monit 1999; 15: 153-162

2. Barbagallo S, Corradi L, de Ville de Goyet J, Iannucci M, Porro I, Rosso N, Tanfani E, Testi A. Optimization and planning of operating theatre activities: an original definition of pathways and process modeling. BMC Med Inform Decis Mak. 2015 May 17;15:38. doi: 10.1186/s12911-0150161-7. PMID: 25982033; PMCID: PMC4436841.

3. Muzumdar D. Safety in the operating room: Neurosurgicalperspective. International Journal of Surgery. 2007 5, 286-288.

4. https://www.who.int/patientsafety/safe surgery/checklist/en/

5. Guidelines for Using HIV Testing Technologies in Surveillance:

Selection, Evaluation and Implementation: 2009 Update. Geneva: World Health Organization; 2009. Appendix, Standard Precautions for Prevention of Transmission of HIV, Hepatitis B Virus, Hepatitis C Virus and Other Bloodborne Pathogens in Health-Care Settings. Available from: following surgery and close theatre for 12 hours. Instruments that cannot be disposed are soaked in $1 \%$ sodium hypochlorite solution for 12 hours and autoclaved for 3 times before used again for another case.

\section{CONCLUSION}

Neurosurgical procedure which are complex and usually carried out over a prolonged period of time, it is very important for the operating personals to ensure safety method for its smooth functioning, and to prevent most medicolegal issues and inadvertent damage to patients, staffs, and surgeons.

https://www.ncbi.nlm.nih.gov/books/ NBK305277/ 